\title{
A prospective study of the study of maternal and perinatal outcome in cases of eclampsia
}

\author{
Sanjay Ravan Ponde*, Preeti Hatkar, Y. S. Nandanwar, Niranjan Chavan
}

Department of Obstetrics and Gynaecology, Lokmanya Tilak Municipal Medical College and General Hospital, Mumbai, Maharashtra, India

Received: 25 July 2016

Accepted: 26 August 2016

\section{*Correspondence:}

Dr. Sanjay Ravan Ponde,

E-mail: drsrponde@yahoo.com

Copyright: ( ) the author(s), publisher and licensee Medip Academy. This is an open-access article distributed under the terms of the Creative Commons Attribution Non-Commercial License, which permits unrestricted non-commercial use, distribution, and reproduction in any medium, provided the original work is properly cited.

\section{ABSTRACT}

Background: This is an observational analytical study carried out in the department of obstetrics and gynecology, in a tertiary care center to determine the factors influencing fetal and maternal outcome, prognosis and complications in booked and unbooked eclamptic cases.

Methods: The present study is a prospective study of perinatal and maternal outcome in 50 cases of eclampsia, above 32 weeks of gestation, from $1^{\text {st }}$ May 2013 to $30^{\text {th }}$ April 2014. Patients with medical complications like anemia, preexisting hypertension, diabetes, vascular or renal disease, multiple gestation, polyhydraminos, etc. are excluded from the study. Detailed history, physical examinations were carried out and appropriate management instituted as per individual patient need. Follow-up of mothers up to 6 weeks postpartum and neonates in the early neonatal period was done.

Results: Incidence of eclampsia is $0.64 \%$, incidence of maternal mortality is $0.4 \%$ and perinatal mortality is $24 \%$. $36 \%$ of patients developed complications. Maternal mortality was significantly high in patients with 6 or more episodes of convulsions. The most common cause of perinatal mortality is prematurity. Antepartum eclampsia with gestational age less than 36 weeks, BP > 160/100, preterm births, low birth weight babies, low apgar scores influenced adverse perinatal outcome.

Conclusions: Eclampsia still remains a major problem in developing countries. It is one of the important causes of maternal and perinatal morbidity and mortality due to lack of proper ANC, low socio-economic status and lack of education.

Keywords: Eclampsia, Hypertension, Maternal death, Perinatal death

\section{INTRODUCTION}

Eclampsia is a life threatening emergency that continues to be a major cause of maternal and perinatal mortality worldwide. Maternal mortality varies widely at different places with almost identical management indicating that there may be important differences in socio-economic conditions of a nation and the quality of obstetric care. According to Doeley's estimation, globally about 50,000 women die of eclampsia annually. In India, maternal mortality and morbidity from eclampsia is very high. The figure ranges from $8-14 \%$. A low maternal mortality of $2.2 \%$ was reported by Menon. ${ }^{1}$ The perinatal mortality ranges from $14.6 \%$ to $47.4 \% .^{2}$ Because "eclampsia still kills", it is worthwhile to periodically review this major problem of obstetric care. ${ }^{3}$

Eclampsia in addition to hemorrhage and embolism is the third leading cause of maternal mortality and morbidity with better antenatal care, early recognition and hospital treatment of severe pre-eclampsia patients, the incidence of eclampsia can be decrease. ${ }^{4}$

The high maternal morbidity and mortality due to eclampsia in the developing countries has been ascribed to late referral, delay in hospitalization, lack of transport, 
unbooked status of patients and multiple seizures prior to admission. ${ }^{5}$

\section{Objective}

- To know the factors influencing fetal and maternal outcome and prognosis in cases of eclampsia like, patient's age, gestational age, mode of delivery and types of complications.

- To find out the effect of interval between onset of convulsions and delivery on the mother and their babies.

- To prevent maternal mortality and morbidity by knowing prognostic factors and by prompt intervention.

- To know the complications and outcome in booked and unbooked antenatal cases.

\section{METHODS}

A total number of 50 cases of eclampsia admitted to Tertiary care general Hospital, from May 2013 to April 2014 were taken into this study. Magnesium sulphate was the drug of choice for management of convulsions. Variables like age, parity, duration of pregnancy, mode of delivery, antenatal check-up and fetal condition were recorded and follow up for mother and baby was carried out.

\section{Inclusion criteria}

- Pregnancy with eclampsia

- Singleton pregnancy

- Gestational age (from 32 weeks till term)

\section{Exclusion criteria}

- Pregnancy associated with medical complications like anemia, pre-existing hypertension, diabetes, vascular or renal disease, thyroid disorders etc.

- Multiple gestation

- Polyhydramnios

- H/o IUGR babies in previous pregnancy

- H/o convulsions secondary to other medical causes

- Post-partum convulsions

- Detailed history was taken regarding the convulsions and physical examination carried out.

In all the cases following investigations were carried out:

- Haemoglobin estimation

- Urine for albumin, sugar and microscopy

- Blood grouping and Rh typing

- Blood urea, Serum uric acid

- Serum creatinine

- LFT

- Fundoscopy
- Serum magnesium (this was an extra investigation done in patients, who had repeat convulsion/s, even after loading dose and maintenance dose of Inj. $\mathrm{MgSO}_{4}$ therapy. Blood samples were obtained immediately or within 10 minutes of episode of repeat convulsions.

All relevant data was compiled and entered into computer using computer based software for appropriate analysis.

\section{Medical management}

\section{Anticonvulsants}

Inj. $\mathrm{MgSO}_{4}$ was used as an anti-convulsant given by Pritchard's regimen: 4 gms of $20 \%$ Inj. $\mathrm{MgSO}_{4}$ in $20 \mathrm{ml}$ of $5 \%$ dextrose was given intravenously slowly over a period of 15-20 minutes followed by 5 gms of 50\% Inj. $\mathrm{MgSO}_{4}$ in each gluteus muscle deep intramuscular. Therapeutic level was maintained by Inj. $\mathrm{MgSO}_{4} 5 \mathrm{gms}$ given every 4 hourly deep IM in alternate buttock and it was continued for 24 hours following delivery. The signs of $\mathrm{MgSO}_{4}$ toxicity were carefully monitored like, absence of patellar reflex, decreased respiratory rate (less than $14 / \mathrm{min}$ ), decrease in the urine output (less than $100 \mathrm{ml}$ in 4 hours). If any signs of toxicity were found, $\mathrm{MgSO}_{4}$ was discontinued. General nursing care, fluid and electrolyte balance were maintained, urine output was monitored with an indwelling catheter.

\section{RESULTS}

Incidence of eclampsia is $0.64 \%$, incidence of maternal mortality is $0.4 \%$ and perinatal mortality is $24 \% .36 \%$ of patients developed complications. Maternal mortality was significantly high in patients with 6 or more episode of convulsions. The most common cause of perinatal mortality was prematurity. Ante partum eclampsia with gestational age less than 36 weeks, BP >160/100, preterm birth, low birth weight babies, low Apgar scores influenced adverse perinatal outcome.

Statistical analysis has been done using the Chi-square test.

$$
\mathrm{X} 2=\sum \frac{(0-\mathrm{E}) 2}{\mathrm{E}}
$$

\section{O: Observed; E: Expected}

Results (both perinatal and maternal deaths) are presented as number and percentages. Chi-square test was used to analyse the categorical data. A p-value of $\leq 0.05$ was considered for statistical significance.

\section{Maternal mortality and morbidity}

There were 2 maternal deaths out of 50 cases; therefore the incidence of maternal mortality is $4 \%$. 
Table 1: Maternal mortality in relation to blood pressure, cause of death and convulsion delivery interval.

\begin{tabular}{|c|c|c|c|c|}
\hline \multirow{2}{*}{ Causes of death } & Causes of death & Acute renal failure & Pulmonary oedema & Total \\
\hline & No of cases & $1(50 \%)$ & $1(50 \%)$ & 2 \\
\hline \multirow{3}{*}{$\begin{array}{l}\text { Maternal death according } \\
\text { to blood pressure }\end{array}$} & Blood pressure in mmhg & $<140 / 90$ & $140 / 90-160 / 110$ & $>160 / 110$ \\
\hline & No of cases & 11 & 17 & 22 \\
\hline & Maternal death & $\mathrm{o}$ & 1 & 1 \\
\hline \multirow{3}{*}{$\begin{array}{l}\text { Death according to } \\
\text { convulsion to delivery } \\
\text { interval }\end{array}$} & C-D interval(hours) & $6-12$ & $13-24$ & $>24$ \\
\hline & No of cases & 16 & 24 & 10 \\
\hline & Maternal death & 0 & 1 & 1 \\
\hline
\end{tabular}

\section{The causes of maternal deaths were}

Majority of cases (48\%) have presented more than 6 hours after onset of convulsions. Maternal mortality increases with increase in first fit - admission interval. However statistically it is not significant.

In this study, majority of the patients belong to low socioeconomic class (94\%), while remaining 6\% belong to middle class. The maternal deaths occurred in the low socio-economic group $(4.3 \%)$. However, this is not statistically significant $(\mathrm{p}=0.72) . \mathrm{X} 2=0.78, \mathrm{p}=0.18$, not significant.

Out of the 50 cases, $54 \%$ were unbooked and $46 \%$ were booked. While 2 maternal deaths $(7.4 \%)$ occurred in unbooked cases and there is maternal death in booked cases. However, statistically this is not significant $(\mathrm{P}=0.18)$. Although maternal mortality was higher in patients with higher admission BP. This was found to be statistically not significant $(\mathrm{P}=0.73)$.

With a convulsion delivery interval of $>24$ hours, maternal mortality was $10 \%$ as against $4.2 \%$ when convulsion delivery interval was 13-24 hours and 0 . \% when convulsion delivery interval was $<12$ hours. However, this was not statistically significant $(\mathrm{P}=0.45)$.

\section{Proteinuria}

Proteinuria was noted in all 50 cases (100\%). Maximum numbers of convulsions are seen in patients with grade $+3,+4$ proteinuria. Maternal mortality is seen in patients having $3+$, and $4+$ of proteinuria.

\section{Oedema}

Oedema was observed in all 50 cases (100\%).

\section{Maternal age}

In patients below 20 years of age, maternal mortality was $7.1 \%$, while it was $3.3 \%$ in age group below 25 years. However, statistically this is not significant $(\mathrm{P}=0.89)$.

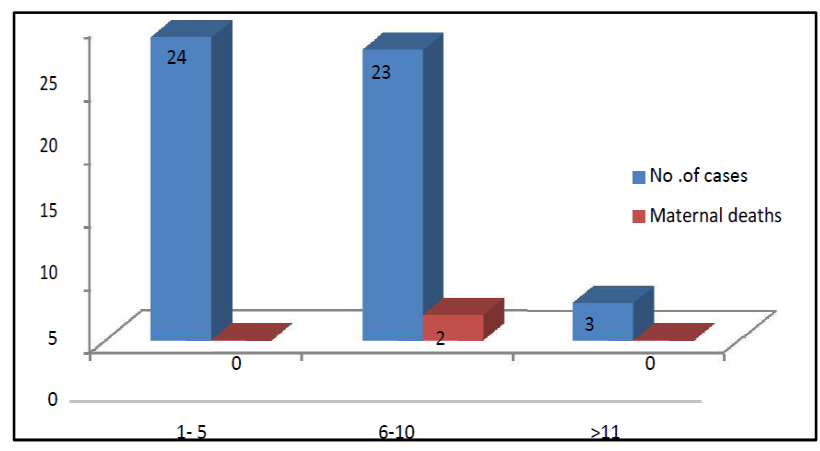

Figure 1: Maternal mortality in relation to first fit admission interval.

Table 2: Maternal mortality in relation to number of convulsions.

\begin{tabular}{|llll|}
\hline $\begin{array}{l}\text { No. of } \\
\text { convulsions }\end{array}$ & $\begin{array}{l}\text { No. of } \\
\text { cases }\end{array}$ & $\begin{array}{l}\text { Maternal } \\
\text { deaths }\end{array}$ & Percentage \\
\hline $1-5$ & 43 & - & - \\
\hline $6-10$ & 7 & 2 & 28.6 \\
\hline Total & $\mathbf{5 0}$ & $\mathbf{2}$ & $\mathbf{4}$ \\
\hline $\mathrm{X}^{2}=12.8, \mathrm{P}$ & $<0.001$, HS (highly significant). \\
\hline
\end{tabular}

Maternal mortality was significantly higher in patients who had 6 or more episodes of convulsions $(\mathrm{P}<0.001)$

Table 3: Maternal complications.

\begin{tabular}{|lll|}
\hline Maternal complications & No. of cases & $\begin{array}{l}\text { Maternal } \\
\text { deaths }\end{array}$ \\
\hline Transient oliguria & 10 & $1(12.5 \%)$ \\
\hline Unconsciousness & 4 & - \\
\hline Abruptio placenta & 2 & - \\
\hline Pulmonary oedema & 1 & $1(100 \%)$ \\
\hline Pyrexia of unknown origin & 1 & - \\
\hline Total & $\mathbf{1 8}$ & 2 \\
\hline
\end{tabular}

Out of 50 cases studied, LSCS was done in 18 patients, so maternal mortality in relation to duration of labor was determined in only 32 patients. There is no statistically significant correlation between duration of labor and maternal mortality $(\mathrm{P}=0.11)$. 


\section{Recurrence of convulsions}

In the present study, out of 50 cases, no patients had recurrence of convulsions. In both loading dose of $2 \mathrm{gm}$ $\mathrm{MgSO}_{4}$ was repeated and maintenance dose was adjusted to $2 \mathrm{gm} / \mathrm{hr}$ following which there was no recurrence of convulsions. So there is no role of measuring serum magnesium levels. In this study out of 50 cases, 18 cases (36\%) developed complications. The common complications were unconsciousness, transient oliguria and pulmonary oedema. The maternal mortality being $12.5 \%, 100 \%$ respectively.

Table 4: Perinatal mortality and morbidity.

\begin{tabular}{|ll|}
\hline Perinatal mortality and morbidity & No. of cases \\
\hline Total number of cases & 50 \\
\hline Total number of babies & 50 \\
\hline Number of live births & 43 \\
\hline Number of cases with absent & 3 \\
\hline FHS at admission & \\
\hline No. of fresh still births & 4 \\
\hline No. of Neonatal deaths & 5 \\
\hline Total perinatal deaths : $3+4+5=12$ & \\
\hline
\end{tabular}

Incidence of uncorrected perinatal mortality is $24 \%$. Incidence of corrected perinatal mortality is $18 \%$ (excluding cases of absent FHS at admission).

Table 5: Causes of neonatal deaths.

\begin{tabular}{|lll|}
\hline Cause of neonatal deaths & No .of cases & Percentage \\
\hline Prematurity & 3 & 60 \\
\hline Septicemia & 2 & 40 \\
\hline Total & $\mathbf{5}$ & $\mathbf{1 0 0 . 0}$ \\
\hline
\end{tabular}

Table 6: Perinatal mortality in relation to number of convulsions.

\begin{tabular}{|clll|}
\hline $\begin{array}{l}\text { No. of } \\
\text { convulsions }\end{array}$ & No. of cases & $\begin{array}{l}\text { Perinatal } \\
\text { deaths }\end{array}$ & Percentage \\
\hline $1-5$ & 43 & 5 & 11.6 \\
\hline $6-10$ & 7 & 7 & 100 \\
\hline Total & $\mathbf{5 0}$ & $\mathbf{1 2}$ & $\mathbf{2 4 . 0}$ \\
\hline
\end{tabular}

$\mathrm{X} 2=25.78 \mathrm{P}<0.001$, highly significant.

Out of 12 perinatal deaths, there were 5 neonatal deaths (41.6\%). The most common cause being pre-maturity (60\%). Perinatal mortality was significantly higher when gestational age was $<36$ weeks. $(\mathrm{P}<0.01)$. The above observation show that perinatal mortality increases as the parity increases. Perinatal mortality being $18.9 \%$ in primiparous women as against $100 \%$ in para 3 and above. This was found to be statistically significant $(\mathrm{P}=0.03)$.

Majority of perinatal deaths were in middle socioeconomic group $33.4 \%$. This was found to be statistically not significant $(\mathrm{P}=0.70)$. Perinatal mortality increases with the number of convulsions. This was found to be statistically significant $(\mathrm{P}<0.001)$.

Perinatal mortality increases with increasing convulsion delivery interval especially when convulsion delivery interval is $>24$ hours. Statistically this was found to be not significant $(\mathrm{P}<0.80)$. Perinatal mortality was significantly less in those delivered by LSCS $(\mathrm{P}=0.02)$. Although there were no maternal death in the 18 cases delivered by LSCS, this was found to be statistically not significant $(\mathrm{P}=1.17)$.

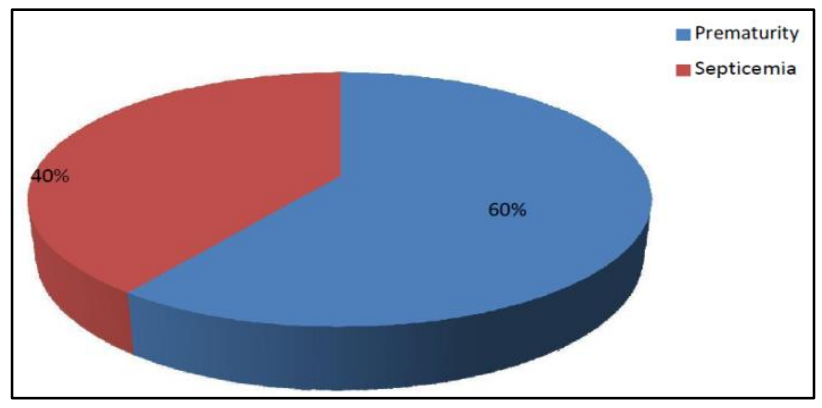

Figure 2: Cause of neonatal death.

\section{DISCUSSION}

The incidence of eclampsia and the total number of deaths from eclampsia have come down dramatically in developed countries. This has been achieved with improvements in prenatal care and management. However, in developing countries eclampsia still stands as one of the major complications of pregnancy.

The incidence in the present study is $0.68 \%$ as against 0.14 to $1.4 \%$ in 2007 reported by Somegouda $\mathrm{S}$ et al, $2.79 \%$ and $1.85 \%$ reported by Kumar AM and Nobis PN, respectively. ${ }^{1,6,7}$ But it is very much higher in comparison to western reports. The higher incidence in the present study is due to, lack of proper antenatal care and also because the study is undertaken in a referral hospital. Almost 40-45\% the patients delivered at our hospital was referred from peripheral hospital for some high risk for maternal fetal or any medical complications so the accurate incidence could not be calculated hence the incidence was not the objective of our study.

\section{Explanation}

Total 95 cases of eclampsia were admitted during last year, out of which 40 were post-partum referred from periphery hospital. Total antenatal eclampsia cases were 55 , out which 5 were with associated medical diseases renal and hypothyroid. Total no of deliveries during one year were 13,970 . $(95 / 13970 * 100=68)$

\section{Socio-economic status}

In this series, most of the women (94\%) had come from the low socio-economic status. According to Saima et al majority of the patients $(67.96 \%)$ belong to low income group. According to Majhi AK, majority of the patients 
(82\%) belonged to poor socio-economic status which is largely related with health consciousness and health and family welfare of the people. ${ }^{7}$ This indicates that socioeconomic status, poor nutrition and inadequate antenatal care, have close relationship with eclampsia and increased perinatal and maternal mortality.

\section{Antenatal care}

In the present study, majority of the women (54\%) were unbooked. Maternal and perinatal mortality in this group was higher. $82 \%$ of eclampsia patients in the study done by Singh SR et al and $82.3 \%$ of patients in that of Majhi AK did not have regular ANC's.?

It has been universally accepted that the adequate standard antenatal care has immense value in reducing the incidence of eclampsia by early detection of preeclampsia and its prompt management. Sibai et al had pointed out nonpreventable eclampsia, the incidence of which was very difficult to reduce. ${ }^{8}$ It was a notable fact in our series also that $46 \%$ of eclamptic women were booked and still developed eclamptic convulsions.

\section{Hypertension, oedema and proteinuria}

In the present study, all patients were hypertensive and all patients had edema and proteinuria. According to Sibai $\mathrm{BM}, 32 \%$ did not have oedema, $23 \%$ had relative hypertension, and $19 \%$ did not have proteinuria at the time of convulsions. ${ }^{9}$ Proteinuria is usually a late development in the course of pre-eclampsia. In this study maximum maternal and perinatal mortality was found when the blood pressure was above 160/110 $\mathrm{mmHg}$. According to Chesley et al, the systolic blood pressure of more than $200 \mathrm{mmHg}$ is included in Eden's criteria to denote the severity of eclampsia and the mortality increases with the severity of eclampsia. ${ }^{10}$

\section{Maternal age and parity}

In this series $88 \%$ of victims were below the age of 25 years and $74 \%$ were nulliparous women. Eclampsia cases were more common in primigravida and young age group. But maternal mortality was high in multigravida. According to Sing KR et al $90 \%$ of cases were $<30$ years and were primigravida. ${ }^{11}$

According to Agustinconde A et al, although nulliparity and young maternal age are well accepted risk factors for eclampsia, they were not found to be associated with the development of complicated eclampsia. ${ }^{12}$ The increased incidence of severe illness in multiparous and older women with eclampsia may be related to the rising prevalence of essential hypertension that occurs with aging. Fisher et al performed kidney biopsies on both nulliparous and multiparous patients with pre-eclampsia. They found prevalence of chronic renal lesions in $16.3 \%$ and $51.0 \%$ respectively. These findings could explain the higher rate of complications found in eclamptic multiparous.

\section{Number of convulsions}

As the saying goes, each fit brings the patient, a step closure towards the grave, this study shows statistically significant correlation with maternal, perinatal mortality and the number of convulsions. The results were similar to those observed by Swain S, Dhananjaya BS and Rajeshri et al. ${ }^{11,13,14}$

\section{Convulsion - delivery interval}

In the present series, convulsion delivery interval is directly proportional to maternal and perinatal mortality. However, increase in maternal mortality with increasing first fit to delivery interval was statistically not significant. Similar observation have been made by Rajeshri et al and Swain S. et al. ${ }^{1411}$ The perinatal mortality increases when the interval between the first fit and the delivery increases, due to prolonged exposure to intrapartum asphyxia.

\section{Duration of labor}

In this study, maternal mortality increased with the increase in the duration of labour. Although statistically not significant, there is direct correlation between the perinatal mortality and duration of labor. This may be due to the simple reason that fetus is exposed to intrauterine asphyxia for a longer time.

\section{Gestational age}

In the present series perinatal mortality was high (70.6\%) when the duration of gestation was $<36$ weeks, which was found to be highly significant $(\mathrm{P}<0.001)$. Similar observations were made by Dhananjaya et al. ${ }^{13}$ Therefore prematurity is of the main cause of high perinatal mortality.

\section{Recurrence of convulsions}

In the present series, out of 50 cases no one had repeat convulsions with Pritchard's regime.

\section{Mode of delivery}

There is no general agreement as to the mode of delivery in eclampsia. Menon et al and Worley et al recommended vaginal delivery in eclampsia reserving caesarean section only for obstetrical reasons. ${ }^{15,16}$ On the other hand Pritchard et al, Chesley et al have favored caesarean section to reduce maternal and perinatal mortality. ${ }^{5,10}$ In our study, also perinatal mortality was lowest (5.6\%) in 18 cases where caesarean section was performed. However, maternal mortality in relation to mode of delivery was statistically not significant.

\section{Maternal and perinatal mortality}

Maternal and perinatal mortality in eclampsia is still very high and no appreciable change has been observed in last 30 years. Menon et al reported a perinatal mortality of $30 \%$ and maternal mortality of $2.2 \%$. 
In the present series, incidence of maternal mortality is $0.68 \%$ and perinatal mortality is $24 \%$. Prematurity is the main cause of neonatal deaths. The high mortality rate in our series is probably due to late arrival of the patients and many in moribund condition. Considerable number of cases has come from far distance ( $80 \%$ from more than $70 \mathrm{kms}$ ). Delay in presentation is due to lack of proper transportation. And most of the cases had received haphazard combination of sedative and anticonvulsants in primary health centers where there is a little or no experience regarding the management of eclampsia. Moreover several patients suffered one or more seizures during their transfer to the hospital. So, proper control of convulsions and blood pressure before and during shifting the patient to higher centers may improve outcome in these cases.

\section{CONCLUSION}

Eclampsia still remains a major problem in developing countries. It is one of the important causes of maternal and perinatal morbidity and mortality due to lack of proper ANC, low socio-economic status and lack of education. In the present series, the incidence of eclampsia is high which is mainly due to the high referral of eclampsia cases, reflecting poor antenatal care. Both maternal and perinatal mortality rate are still disappointing. One maternal death occurs in every 25 eclamptic women.

Early attention and intensive management are essential for improving the maternal and fetal outcome in eclamptic cases. Unless the social and educational status of women is uplifted and obstetric care is brought to the doorstep, no miracle can be expected. A moderate reduction of death of mother and fetus in our institution was possible due to wider use of magnesium sulphate, timed delivery, and proper implementation of emergency obstetric care facilities to mother with eclampsia. Moreover, this is a study done in referral centre and the actual situation in the society as a whole remains unclear.

\section{Funding: No funding sources}

Conflict of interest: None declared

Ethical approval: The study was approved by the Institutional Ethics Committee

\section{REFERENCES}

1. Nobis PN. Maternal outcome in eclampsia. Asian $\mathbf{J}$ Obstet Gynaec Practice. 2002;6(1):25-8.
2. Varawalla NY, Ghamande S, Ingle KM. A five year analysis of eclampsia. J Obstet Gynaecol Ind. 1989;39:513-5.

3. Miles JF, Martin JN, Blake PG, Perry KG, Martin RW, Meeks GR. Postpartum eclampsia : a recurring perinatal dilemma. Obstet Gynaecol. 1990;76:32831.

4. Gary CF. Williams obstetrics. $21^{\text {st }}$ Edition. New York:McGraw Hill. 2001:567-618.

5. Fernando A. Practical guide to high risk pregnancy and delivery. $2^{\text {nd }}$ Edition. USA:Mosby;1998:183207.

6. Suman GS, Somegowda. Factors affecting maternal and perinatal outcome in eclamspia. J Obstet Gynecol India. 2007:57.

7. Majhi AK, Chakraborty PS, Mukhopadhyay A. Eclampsia - present scenerio in a referral medical college hospital. J Obstet Gynaecol India. 2001;51(3):143-7.

8. Baha SM, Mccubbin JH, Anderson GD, Lipshitz J, Dilts PV. Eclampsia I. Observations from 67 recent cases. Obstet Gynecol. 1981;58:609-13.

9. Baha SM. Eclampsia VI. Maternal-perinatal outcome in 254 consecutive cases. Am J Obstet Gynecol. 1990;163:1049-55.

10. Chesley LC. Hypertensive disorders in pregnancy. New York: Appleton.Century Crofts;1978:1-628.

11. Swain S, Ojha KN, Prakash A, Bhatia BD. Maternal and perinatal mortality due to eclampsia. Indian $\mathbf{J}$ Paediat. 1993;30(6):771-3.

12. Conde A, Goeta ACK. Case - control study of risk factors for complicated eclampsia. Obstet Gynecol. 1997;90:172-5.

13. Dhananjay BS, Dayananda G. A study of factors affecting perinatal mortality in eclampsia. Journal of Pharmacy and Bioallied Sciences. 2009;22(2):2-5.

14. Rajesri et al. Eclampsia and perinatal outcome - A retrospective study in teaching hospital. J of Clinical and Diagnostic Research 2011;5(5): 1056-1059

15. Menon MKK. The evolution of the treatment of eclampsia. J Obstet Gynaec. 1961;68:17.

16. Richard F, Worley. Eclampsia. Progress in obstetrics and gynaecology. $3^{\text {rd }}$ Edition. John Studd, London:Churchill Livingstone;1984:183-96.

17. Dutta DC. Text book of obstetrics. $4^{\text {th }}$ edition. Calcutta: New Central Book Agency Pvt Ltd;1998:234-54.

18. Teaching hospital, gwagwalada, abuja: a 3 year review. Nigeria J Clin Pract. 2009:134394.

Cite this article as: Ponde SR, Hatkar P, Nandanwar YS, Chavan N. A prospective study of the study of maternal and perinatal outcome in cases of eclampsia. Int J Reprod Contracept Obstet Gynecol 2016:5:3433-8. 